\title{
Religious Conversion Practices and LGBTQA + Youth
}

\author{
Tiffany Jones ${ }^{1}\left[\right.$ ] Jennifer Power ${ }^{2} \cdot$ Adam O. Hill $^{2} \cdot$ Nathan Despott $^{3} \cdot$ Marina Carman $^{2} \cdot$ Timothy W. Jones $^{4}$. \\ Joel Anderson ${ }^{2} \cdot$ Adam Bourne $^{2}$
}

Accepted: 28 June 2021 / Published online: 6 July 2021

(c) The Author(s) 2021

\begin{abstract}
Introduction Multiple jurisdictions are debating responses to United Nations calls for banning attempts at conversion of lesbian, gay, bisexual, transgender, queer and asexual (LGBTQA+) peoples' identities to fit religious norms. This paper aimed to examine Australian LGBTQA + youths' experiences and outcomes of religious conversion practices attempting to change or suppress their gender or sexuality. It explored how attending conversion practices related to demographic characteristics and outcomes.

Methods A 2019 online health and social well-being survey promoted via diverse social media questioned 6412 LGBTQA + Australians aged 14-21 years on their experiences of sexuality or gender change or suppression practices. Descriptive and inferential analyses were performed to understand relationships between exposure to conversion practices and demographic, socio-behavioural, and health and well-being measures.

Results Whilst most participants had never attended counselling, group work, programs or interventions aimed at changing their sexuality or gender identity, $4 \%$ had attended such conversion practices. Analyses showed associations between engaging with conversion practices and (1) specific demographics (being cisgender male, multi-gender-attracted, unemployed, affiliated to a religion at the personal or household level); (2) social experiences (increased exposure to social rejection, negative remarks and harassment); (3) socio-behavioural outcomes (decreased education, sport and housing opportunities) and (4) negative health and mental health outcomes (including increased suicidality and self-harm).

Conclusions The paper showed that conversion practices are correlated with poor well-being outcomes, providing arguments for expanding inclusive health and mental health services allowing for affirming religious and non-religious identities for LGBTQA + youth.

Policy Implications The paper provides evidence supporting bans on conversion practices.
\end{abstract}

Keywords Religion $\cdot$ Conversion $\cdot$ Suicide $\cdot$ Youth $\cdot$ Sexual orientation $\cdot$ Gender identity

\section{Introduction}

Countries are responding to the United Nations' (2020) calls for banning attempts at 'converting' lesbian, gay, bisexual, transgender, queer, asexual and other diverse (LGBTQA +) people to fit religious cisgender heteronormative ideals.

Tiffany Jones

Tiffany.Jones@mq.edu.au

1 School of Education, Macquarie University, Room 368, Level 3, 29 Wally's Walk, Sydney, NSW 2109, Australia

2 Australian Research Centre in Sex Health and Society, La Trobe University, VIC, Bundoora, Australia

3 Brave Network/Inclusion, Melbourne, VIC, Australia

4 School of Humanities and Social Sciences, La Trobe University, Bundoora, VIC, Australia
Brazil, Ecuador, Malta and Taiwan banned conversion therapy whilst Canada, Spain and the United States (US) debate localised restrictions (United Nations, 2020; 9). Bans are operating in Australia's Capital Territory, Queensland and Victoria (ACT Government, 2020; QLD Government, 2020; Victorian Government 2021); emerging in Tasmania, South Australia and Western Australia (Hill, 2019; Richards \& Skujins, 2020; WA Parliamentary Council, 2020); and debated in New South Wales and the Northern Territory. Grounded in critical emancipatory perspectives with a peerled group of LGBTQA + self-titled 'survivors' of diverse conversion ideology and practices, the Sexual Orientation and Gender Identity Change Efforts Survivor Statement outlines survivor-led definitions of 'conversion ideology' as overt spoken beliefs/teachings, and the underlying culture of 
a particular community of people that sees LGBTQA + identity as somehow 'broken' or 'sinful', and in need of 'fixing' or suppression to achieve heterosexual reproductive marriage and gender normativity within a largely binary sex/ gender model that aligns with the sex marker assigned at birth (Csabs et al., 2020). Conversion ideology thus goes beyond religion itself, or religious anti-LGBTQA + bias. Within conversion ideology, core religious assertions (like religious rejection threats) are distinct from pseudoscientific false and misleading claims that use psychological language to explain the origins, causes or 'dysfunction' of LGBTQA + identities because they are within democratic governments' intervention scope through laws and ethics codes (United Nations, 2020; Australian Psychological Society, 2007).

Hence 'conversion practices' comprises of processes engaged in towards desired changes in gender and/or sexuality based in conversion ideology. Conversion practices may include (but are not limited to) counselling, group work, programs or interventions (perhaps therapeutic/corrective prayer, performing celibacy or endorsed sexual relationships, personal or group behavioural suppression, etc.). These practices can be formal or informal, and regionally variable-such as witchdoctor exorcisms in Mozambique (United Nations, 2020). Health, well-being and education professionals are hindered in responding to legislative changes due to limited conversion research, especially on LGBTQA + youth (Australian Institute of Family Counselling, 2017; Health Complaints Commissioner, 2019). This paper firstly outlines existing research on conversion ideology and practices, and secondly reports on data drawn from an online LGBTQA + youth survey, specifically designed to explore questions pertaining to engagement with conversion practices.

International conversion research mostly includes USbased psychological studies - with the American Psychological Association (APA) and other psychological bodies' task forces underlining conversion's ineffectiveness (Serovich et al., 2008; Beckstead, 2020; APA Task Force, 2009). Fewer socio-behavioural studies explore regional conversion ideology movements-typically emphasising white evangelical Christian gay adult males and 1970s + emergence of conversion practices in Evangelical and Pentecostal communities, and suggesting 1990s + emergence of 'ex-trans' genderrelated practices (Bennett, 2003; Bishop, 2019; Erzen, 2006; Gerber, 2012; Waidzunas, 2015; Wolkomir, 2006). There is also emphasis on the autobiographical processes-(re-)presenting one's own history towards explaining one's identity formations and 'progress' - core to many conversion practices (Bennett, 2003; Keane, 2009; Mac-Iyalla, 2014; Venn-Brown, 2015; Yarhouse, 2015).

Insufficient research maps conversion exposure prevalence for LGBTQA + youth, with between 7 and $16+\%$ of LGBTQ + adults reporting some exposure depending on country-the higher figures were reported in Iran and South Korea (Bishop, 2019; Jones, 2015; UK Government Equalities Office, 2018). UK-based research on 108,100 LGBTQ + people found that $7 \%$ were offered conversion practices, $2 \%$ undertook them (UK Government Equalities Office, 2018)—including 4\% of trans men. US research on LGBTQA + adults estimated that over half of adults exposed to conversion ideology were also exposed as adolescents (Mallory et al., 2019). A study of 3134 Australian LGBTIQA + youth found that $7 \%$ were exposed to the conversion ideology messaging 'gay people should become straight' in schools (Jones, 2015; Jones \& Hillier, 2012) - more in Catholic (15.4\%) and Other Christian (16.4\%) schools than government schools (3.6\%). Students at schools with anti-homophobia policies had reduced exposure (3.9\% vs. $14.3 \%$ without policies). Another study showed that $4.9 \%$ of 2500 mostly heterosexual cisgender Australian students were exposed to this conversion ideology school-based messaging: over a tenth in ideologically conservative schools (those schools inculcating students with the status quo's traditionalist values within a top-down power structure, Jones, 2020). These students reported greater harms to concentration, grades and attendance due to abuse at school than those not exposed to conversion ideology. They were significantly more likely to consider self-harm (81.8\%); engage in self-harming behaviours (61.8\%); consider suicide (83.6\%); and attempt suicide $(29.1 \%)$. Conversion ideology is clearly in operation across multiple contexts internationally including schools, and harmful. Quantitative studies of the prevalence and impacts for LGBTQA + youth attending conversion practices however, are lacking.

A survey-based study was developed to explore these research gaps to explore prevalence and outcomes of Australian LGBTQA + youths' exposure to conversion practice. The survey was conducted in advance of conversion bans so these data can be explored in comparison to international data and over time. Using Mallory et al. (2019) estimates, the team hypothesised that Australian youth may report conversion practices to at least half the $7+\%$ prevalence rates of LGBTQ + adults' exposure to conversion ideology messaging across Western contexts, and may experience harmful effects. The study addressed four research questions:

1. Do Australian LGBTQA + youths' conversion practice attendances differ by demographic factors?

2. What is the relationship between conversion practice attendance and social experiences?

3. What is the relationship between conversion practice attendance and socio-behavioural outcomes?

4. What is the relationship between conversion practice attendance and individual health and well-being? 


\section{Methods}

The findings discussed in this paper are based on a section of the Writing Themselves in 4 survey-the latest in a series of cross-sectional health and social well-being surveys of LGBTQA + young people in Australia (aged 14-21 years) (Hillier, et al., 2010). It was approved by the La Trobe University Human Research Ethics Committee. The survey instrument comprised items pertaining to basic demographic characteristics including age, area of residence, gender, sexuality, education and employment. Questions were included that sought to understand whether survey participants had experience of attending counselling, group work, programs or other interventions aimed at changing their sexuality or gender identity (formal conversion practices). Response options included 'yes', 'no', 'don't know' and 'prefer not to say'. Those indicating 'yes' were subsequently asked to indicate whether they had this experience within the last 12 months or more than 12 months ago. These questions were developed with expert advice from a local organisation that works to support survivors of conversion practices (We The Brave) in collaboration with community advisory boards.

Self-rated health was measured using the validated 5-point self-rated health (SRH) scale (Bombak, 2013). Psychological distress was measured using the Kessler Psychological Distress Scale (K10), a ten-item standardised scale developed to measure psychosocial distress in the past 4 weeks validated among young people in Australia (Australian Bureau of Statistics, 2012). Suicidal ideation was defined as 'experiences of thoughts about suicide, wanting to die, or about ending your life', suicide plans as having 'made a plan to attempt suicide or end your own life', suicide attempts as having 'attempted suicide or to end your life', self-harm ideation as 'thoughts about harming yourself on purpose' and self-harm as 'injured or harmed yourself on purpose'.

Homelessness was measured as any lifetime experiences of having (1) run away, (2) left home because of being asked to leave, (3) couch surfed or (4) been homeless, based on a previously established measure of homelessness among young people in the US (36). Lifetime experiences of harassment or assault based on participant sexuality or gender identity were measured as follows: verbal (e.g. been called names or threatened); physical (e.g. being shoved, punched or injured with a weapon); and sexual (e.g. unwanted touching, sexual remarks, sexual messages or being forced to perform any unwanted sexual act). Participants were asked if they had disclosed their sexual identity or gender identity to friends, family or classmates. Response options included 'never', 'a few of them', 'some of them', 'most of them' and 'all of them'. Responses were dichotomised to 'any' or 'none' for analyses. Participants who responded they had disclosed their sexual identity or gender identity were asked how supported they feel. Responses were dichotomised from a five-point scale ranging from 'very unsupportive' to 'very supportive' into 'not supported' and 'supported/very supported' for analyses.

Data were collected from 2 September to 28 October 2019, following past social media recruitment strategies (Hillier et al., 2010), including Facebook/Instagram advertising. There were 6418 valid responses from LGBTQA + Australians aged 14-21 years. Data were downloaded into excel and SPSS. Descriptive and inferential statistical analyses examined relationships between conversion practices and: (a) demographics; (b) social experiences; (c) socio-behavioural outcomes and (d) health and well-being.

\section{Results}

Analyses involving categorical independent variables were $\chi^{2}$ tests of independence (bivariate) or log-linear analyses (multivariate). Prior to these analyses being conducted, assumptions of these statistical tests were assessed, and all were upheld for each analysis (i.e. assumed independence of observations, all groups were mutually exclusive, expected count per call $>5$, etc.). Analyses using continuous independent variables were between subject t-tests. Again, for each analysis, all relevant assumptions were assessed and upheld (i.e. all data were normally distributed, homogeneity of variance, etc.).

\section{Sample Characteristics}

The 6418 participants were LGBTQA + youth aged between 14 and 21 years $(M=17.3, S D=2.06)$. Overall, $11.0 \%$ were born overseas and 3.9\% were Aboriginal or Torres Strait Islander. Over 60 languages were spoken among 5.1\% of youth speaking languages besides English at home, most commonly Chinese (16.6\%). Participants were drawn from all Australian states and territories: Victoria (28.9\%), New South Wales (25.2\%), Queensland (15.7\%), Western Australia (11.3\%), South Australia (9.9\%), Australian Capital Territory $(4.7 \%)$, Tasmania (3.5\%) and Northern Territory $(0.1 \%)$. Selecting the best fit description, two-thirds reported they resided in a capital city $(65.6 \%)$, a quarter $(24.9 \%)$ in regional cities or towns and $10.5 \%$ in rural/remote regions. Most participants were cisgender females (50.6\%) and males (22.3\%), and over a quarter were gender diverse (27.2\%). Twenty were born with intersex variations $(0.003 \%)$. In total, $33.8 \%$ of participants identified as bisexual ( $45.3 \%$ of females), $16.6 \%$ gay (56.4\% of males), $12 \%$ lesbian, $11.2 \%$ pansexual, $8.4 \%$ queer, $4.6 \%$ asexual and $13.4 \%$ used other (or eschewed) labels. 
Of 6412 LGBTQA + youth who answered the question 'Have you ever attended counselling, group work, programs or interventions aimed at changing your sexuality or gender identity?', 256 (4.2\%) indicated that they had attended conversion practices; of the remaining 5949 who indicated that they had not attended such a practice, 159 indicated that they did not know and 48 indicated that they preferred not to say. For parsimony, the latter two groups were excluded from analyses; thus, all analyses presented hereafter are a comparison of those participants who reported they had attended conversion practices with those who reported that they had not attended such practices. Of the 265 individuals who had attended conversion practices, 144 (56.3\%) reported that this occurred in the last 12 months. For prudence, and because we did not ask details about how recent the practices were outside of 12 months, the data supplied from these individuals form the corpus presented in this paper.

\section{Conversion Practices Attendance and Demographic Factors}

A series of analyses were conducted to uncover associations between previous conversion practice attendance and LGBTQA + youths' demographic factors (age, gender diversity, gender, sexual attraction, personal and household religious affiliation, country of birth and employment status). Age was the only a demographic factor measured on a continuous scale. As such, a between-subject t-test was used to test if there were differences in the average age of individuals who had versus those who had not attended conversion practices. The analysis revealed that there were no differences in age between those who attended $(M=17.16, S D=2.11)$ and those who did not $(M=17.32$ , $S D=2.06), t(6203)=1.185, p=0.236$, Cohen's $d=0.076$.

The remaining demographic variables were categorical, and so a series of $\chi^{2}$ tests of independence were performed to examine the relation between each variable and conversion practice attendance (Table 1). The analyses revealed there was no association for gender diversity or country of birth - thus, cisgender and gender diverse participants were equally likely to have attended conversion practices, as were individuals born in Australia compared to overseas. Significant associations were revealed for the remaining variables: gender, sexual identity, personal and household religious affiliation and employment status.

Specifically, there was a significant association between conversion practice attendance and being cisgender male, multi-gender-attracted, religion-affiliated (at either the personal or household level) and unemployed (in comparison
Table 1 Frequency (\%) of LGBTIQA + youths' demographic factors as a function of attending or not attending conversion practices

\begin{tabular}{|c|c|c|c|c|}
\hline \multirow[b]{2}{*}{ Variable } & \multicolumn{2}{|c|}{ Conversion practice attendance, $N(\%)$} & \multicolumn{2}{|c|}{ Statistics } \\
\hline & Attended & Not attended & $\overline{\chi^{2}}$ & $p$ \\
\hline Gender diversity & & & 2.49 & .114 \\
\hline Cisgender & $190(3.5 \%)$ & $4705(96.1 \%)$ & & \\
\hline Trans or gender diverse & $46(5.0 \%)$ & $874(95.0 \%)$ & & \\
\hline Binary (cis) gender & & & 47.91 & $<.001$ \\
\hline Male & $115(6.5 \%)$ & $1670(93.5 \%)$ & & \\
\hline Female & $74(2.4 \%)$ & $2994(97.6 \%)$ & & \\
\hline Sexual attraction & & & 5.54 & .019 \\
\hline Single (same-)gender-attracted & $90(47.1 \%)$ & $1689(38.6 \%)$ & & \\
\hline Multi-gender-attracted & $101(52.9 \%)$ & $2683(61.4 \%)$ & & \\
\hline Personal religious affiliation & & & 16.76 & $<.001$ \\
\hline Religion & $93(36.3 \%)$ & $1576(26.5 \%)$ & & \\
\hline No religion & $163(63.7 \%)$ & $4373(73.5 \%)$ & & \\
\hline Household religious affiliation & & & 16.39 & $<.001$ \\
\hline Religion & $108(42.2 \%)$ & $1628(27.4 \%)$ & & \\
\hline No religion & $148(57.8 \%)$ & $4316(72.26)$ & & \\
\hline Country of birth & & & 2.73 & .090 \\
\hline Australia & $220(85.9 \%)$ & $5307(89.2 \%)$ & & \\
\hline Overseas & $36(14.1 \%)$ & $641(10.8 \%$ & & \\
\hline Employment & & & 5.95 & .015 \\
\hline Unemployed & $146(58.2 \%)$ & $2946(50.3 \%)$ & & \\
\hline Employed & $105(41.8 \%)$ & $2910(49.7 \%)$ & & \\
\hline
\end{tabular}

Variables that are associated with attendance at conversion practices at a statistically significant level $(p<.05)$ are presented in boldface 
to being cisgender female, same-gender-only-attracted, without religious affiliation or employed, respectively).

A log-linear analysis was conducted to predict conversion practice attendance from each of these variables. For parsimony, only the five variables with a significant bivariate association with attendance were included in the model, and only their main effects were tested (i.e. excluding interactions between variables). A test of the model with the five predictor variables against a model with only the constant was statistically significant, suggesting that the predictors (as a set) can reliably distinguish between individuals who have vs. have not attended conversion practices $\chi^{2}(5)=53.36$, $p<0.001$, and that this model is a good fit (Hosmer-Lemeshow statistic $=3.29, p=0.915)$. The prediction success of the model was $96.2 \%$ (Table 2 shows coefficients). Cisgender males in the sample were almost two-and-a-half times more likely than cisgender females to have attended conversion practices, and individuals who had attended conversion practices were $\sim 50 \%$ more likely to come from a religious household and to be unemployed.

\section{Conversion Practices Attendance and Social Experiences}

A series of between-subject $t$-tests were used to test if there were differences in social experiences for Australian LGBTQA + youth who had and had not attended conversion practices (Table 3 ). Those who had attended conversion practices were more likely than those who had not attended to be out to: family, friends, co-workers, classmates, teachers and sports teammates.

Importantly, of those participants who were out, those who had attended a conversion practice were more likely to have non-supportive responses to their disclosure from their family and classmates (although not from their friends, coworkers, teachers or sport teammates). Additionally, those who had attended conversion practices were more likely to have answered 'yes' to questions on whether they had heard negative remarks about sexuality, gender expression, trans people and people with intersex variations in their place of education, and about trans people and people with intersex variations in their places of employment, than those who had not attended.

Chi-square tests of independence were performed to examine the relationships between experiences of harassment and conversion practice attendance (Table 4). There was an association for all types of harassment: those who attended conversion practices were four-and-a-half times more likely to have experienced verbal and physical harassment, and almost three times as likely to have experienced sexual harassment, than those who had not attended.

\section{Conversion Practices Attendance and Socio-Behavioural Outcomes}

Chi-square tests of independence were performed to examine the relation between LGBTQA + youths' socio-behavioural outcomes and conversion practice attendance (Table 5). There were associations between having conversion practice attendance and being more likely to have answered in the affirmative to specific questions measuring: increased drug use and smoking, feeling less safe at place of education, higher levels of truancy and unemployment, greater homelessness (and for that homelessness to be specific to their being LGBTQA +) and decreased sport participation (specifically to avoid sport in order to avoid discrimination). This association was not significant for alcohol consumption or being enrolled in education.

\section{Conversion Practice Attendance and Health and Well-being}

A series of between-subject $t$-tests were used to test if there were differences in self-reported current psychological health between LGBTQA + youth who had and had not attended conversion practices (Table 6). Those who had attended reported increased symptomology of anxiety and
Table 2 Coefficients of the model predicting conversion practice attendance from of LGBTIQA + youths' demographic factors

\begin{tabular}{|c|c|c|c|c|c|c|c|}
\hline & \multirow[b]{2}{*}{$B$} & \multirow[b]{2}{*}{$S E B$} & \multicolumn{3}{|c|}{$95 \%$ CI for odds ratio } & \multirow[b]{2}{*}{ Wald } & \multirow[b]{2}{*}{$p$} \\
\hline & & & Lower & Odds & Upper & & \\
\hline Binary (cis)gender & 0.89 & .018 & 1.70 & 2.44 & 3.49 & 23.76 & $<.001$ \\
\hline Sexual attraction & 0.17 & .019 & 0.83 & 1.18 & 1.68 & 0.83 & .362 \\
\hline Personal religious affiliation & -0.22 & .018 & .055 & 0.80 & 1.16 & 1.37 & .242 \\
\hline Household religious affiliation & -0.66 & .017 & 0.36 & 0.52 & 0.74 & 13.05 & $<.001$ \\
\hline Employment & 0.38 & 0.22 & 1.04 & 1.46 & 2.05 & 4.77 & .029 \\
\hline
\end{tabular}

Bootstrap confidence intervals based on 1000 samples. Constant: $B=-3.33(S E=0.22)$. Variables significantly predicting attendance at conversion are presented in boldface $(p<.05)$. Dichotomous variables coded: gender $(1=$ male, $0=$ female); sexual attraction $(1=$ same-gender only attracted, $0=$ multi-genderattracted $)$; religious affiliations $(1=$ no affiliation, $0=$ religious affiliation $)$; employment $(1=$ unemployed, $0=$ employed) 
Table 3 Mean (SD) of LGBTIQA + youths' outness and level of support to disclosure as a function of attending or not attending conversion practices

\begin{tabular}{|c|c|c|c|c|c|}
\hline & \multicolumn{2}{|c|}{$\begin{array}{l}\text { Conversion practice attendance, } M \\
(S D)\end{array}$} & \multicolumn{3}{|c|}{ Statistics } \\
\hline & Attended & Not attended & $t$ & $p$ & Cohen's $d$ \\
\hline \multicolumn{6}{|l|}{ Outness index } \\
\hline Family & $2.92(1.33)$ & $2.44(1.30)$ & -4.95 & $<.001$ & $\mathbf{0 . 3 7}$ \\
\hline Friends & $4.02(1.13)$ & $3.72(1.23)$ & -3.21 & .001 & 0.25 \\
\hline Co-workers & $2.18(1.47)$ & $1.90(1.29)$ & -0.51 & .611 & $\mathbf{0 . 2 0}$ \\
\hline Classmates & $2.84(1.47)$ & $2.42(1.31)$ & -3.12 & .002 & $\mathbf{0 . 3 0}$ \\
\hline Teachers & $2.39(1.53)$ & $1.66(1.13)$ & -5.91 & $<.001$ & 0.54 \\
\hline Sports teammates & $1.97(1.45)$ & $1.61(1.17)$ & -2.19 & .029 & 0.27 \\
\hline \multicolumn{6}{|c|}{ Non-supportive responses to disclosure } \\
\hline Family & $3.15(1.33)$ & $3.57(1.10)$ & 4.48 & $<.001$ & 0.36 \\
\hline Friends & $4.32(0.91)$ & $4.39(0.87)$ & 1.24 & .217 & 0.08 \\
\hline Co-workers & $3.79(1.06)$ & $3.75(0.90)$ & -0.29 & .770 & 0.04 \\
\hline Classmates & $3.21(1.03)$ & $3.38(0.88)$ & 1.97 & .049 & 0.18 \\
\hline Teachers & $3.80(0.93)$ & $3.80(0.88)$ & 0.04 & .969 & 0.00 \\
\hline Sports teammates & $3.63(1.00)$ & $3.83(0.91)$ & 1.40 & .161 & 0.18 \\
\hline \multicolumn{6}{|c|}{ Negative remarks at place of education about... } \\
\hline Sexuality & $3.39(0.86)$ & $3.17(0.97)$ & -3.78 & $<.001$ & 0.24 \\
\hline Gender expression & $3.00(1.04)$ & $2.74(1.09)$ & -3.84 & $<.001$ & 0.25 \\
\hline Transgender folk & $2.83(1.11)$ & $2.39(1.06)$ & -6.12 & $<.001$ & 0.41 \\
\hline Intersex variation & $1.93(1.16)$ & $1.53(0.87)$ & -5.17 & $<.001$ & $\mathbf{0 . 3 9}$ \\
\hline \multicolumn{6}{|c|}{ Negative remarks at place of employment about... } \\
\hline Sexuality & $2.27(1.23)$ & $2.10(1.11)$ & -1.44 & .154 & 0.15 \\
\hline Gender expression & $2.18(1.17)$ & $2.02(1.06)$ & -1.48 & .142 & 0.14 \\
\hline Transgender folk & $1.95(1.13)$ & $1.59(0.92)$ & -3.21 & .002 & 0.35 \\
\hline Intersex variation & $1.52(0.90)$ & $1.28(0.67)$ & -2.82 & .006 & $\mathbf{0 . 3 0}$ \\
\hline
\end{tabular}

Variables significantly predicting attendance at conversion are presented in boldface $(p<.05)$

$M$ statistical mean, $S D$ standard deviation psychological distress and reported less health and wellbeing than those who had not attended.

A series of $\chi^{2}$ tests of independence were performed to examine the relationships between attendance at a conversion practice and both suicidality and selfharming behaviours (Table 7). The analyses revealed an association between having attended a conversion practice and suicidality: specifically, individuals who had attended a conversion practice were over two-anda-half times more likely to think about or plan suicide, and almost four times more likely to attempt suicide, than individuals who had not attended a conversion practice. Chi-square tests of independence were conducted to see if previous conversion practice attendance was associated with any previous mental health diagnoses (Table 8). There was an association between having

Table 4 Frequency (\%) of LGBTIQA + youths' negative social experiences as a function of attending or not attending conversion practices

\begin{tabular}{|c|c|c|c|c|c|c|c|}
\hline & \multicolumn{2}{|c|}{ Conversion practice attendance, $N(\%)$} & \multicolumn{2}{|c|}{$\begin{array}{l}\text { No conversion practice attendance, } \\
N(\%)\end{array}$} & \multirow[b]{2}{*}{$\chi^{2}$} & \multirow[b]{2}{*}{$p$} & \multirow[b]{2}{*}{ Odds ratio } \\
\hline & $\begin{array}{l}\text { Experiences of } \\
\text { harassment }\end{array}$ & $\begin{array}{l}\text { No experiences of } \\
\text { harassment }\end{array}$ & $\begin{array}{l}\text { Experiences of } \\
\text { harassment }\end{array}$ & $\begin{array}{l}\text { No experiences of } \\
\text { harassment }\end{array}$ & & & \\
\hline \multicolumn{8}{|c|}{$\begin{array}{l}\text { Harassment or } \\
\text { assault type }\end{array}$} \\
\hline Verbal & $214(84.9 \%)$ & $38(15.1 \%)$ & $3187(55.7 \%)$ & $2532(44.3 \%)$ & 142.70 & $<.001$ & 4.47 \\
\hline Physical & $94(42.2 \%)$ & $129(57.8 \%)$ & $679(13.4 \%)$ & $4379(86.6 \%)$ & 2620.60 & $<.001$ & 4.70 \\
\hline Sexual & $117(52.9 \%)$ & $104(47.1 \%)$ & $1442(27.8 \%)$ & $3739(72.2 \%)$ & 940.10 & $<.001$ & 2.92 \\
\hline
\end{tabular}

Variables significantly predicting attendance at conversion are presented in boldface $(p<.05)$ 
Table 5 Frequency (\%) LGBTIQA + youths' socio-behavioural outcomes as a function of attending or not attending conversion practices

\begin{tabular}{|c|c|c|c|c|c|c|c|}
\hline & \multicolumn{2}{|c|}{$\begin{array}{l}\text { Conversion practice attend- } \\
\text { ance, } \\
N(\%)\end{array}$} & \multicolumn{2}{|c|}{$\begin{array}{l}\text { No conversion practice attend- } \\
\text { ance, } \\
N(\%)\end{array}$} & \multirow[b]{2}{*}{$\chi^{2}$} & \multirow[b]{2}{*}{$p$} & \multirow[b]{2}{*}{ Odds ratio } \\
\hline & Reported & Not reported & Reported & Not reported & & & \\
\hline Drink alcohol & $166(64.8 \%)$ & $90(35.2 \%)$ & $3779(63.5 \%)$ & $2170(36.5 \%)$ & 0.18 & .667 & 1.05 \\
\hline Drug use & $94(43.3 \%)$ & $123(56.7 \%)$ & $1725(33.0 \%)$ & $3498(67.0 \%)$ & 9.89 & .002 & 1.55 \\
\hline Smoking & $44(17.2 \%)$ & $212(82.8 \%)$ & $668(11.2 \%)$ & $5277(88.8 \%)$ & 8.55 & .004 & 1.64 \\
\hline Felt unsafe at place of education & $157(70.1 \%)$ & $67(29.9 \%)$ & $2594(49.4 \%)$ & $2660(50.6 \%)$ & 36.89 & $<.001$ & 4.77 \\
\hline Truancy & $170(66.4 \%)$ & $86(33.6 \%)$ & $2336(39.3 \%)$ & $3613(60.7 \%)$ & 75.08 & $<.001$ & 3.06 \\
\hline Unemployment & $146(58.2 \%)$ & $105(41.8 \%)$ & $2946(50.3 \%)$ & $2910(49.7 \%)$ & 5.95 & .015 & 1.37 \\
\hline Enrolled in education & $242(94.5 \%)$ & $14(5.5 \%)$ & $5672(95.3 \%)$ & $277(4.7 \%)$ & 0.36 & .547 & 0.84 \\
\hline Homelessness & $112(44.4 \%)$ & $140(55.6 \%)$ & $1309(22.2 \%)$ & $4591(77.8 \%)$ & 67.40 & $<.001$ & 2.81 \\
\hline LGBTI-specific homelessness & $57(51.4 \%)$ & $54(48.6 \%)$ & $308(23.7 \%)$ & $993(76.3 \%)$ & 40.87 & $<.001$ & 3.40 \\
\hline Played sport & $163(63.7 \%)$ & $93(36.3 \%)$ & $2394(40.4 \%)$ & $3538(59.6 \%)$ & 55.02 & $<.001$ & 2.59 \\
\hline Avoided sport to avoid discrimination & $37(55.2 \%)$ & $30(44.78 \%)$ & $237(12.61 \%)$ & $1642(87.39 \%)$ & 97.10 & $<.001$ & 8.54 \\
\hline
\end{tabular}

Variables that are associated with attendance at conversion practices at a statistically significant level $(p<.05)$ are presented in boldface

attended conversion practices and being more likely to have had a diagnosis for all 10 mental health conditions considered (listed in Table 8). The odds ratios (range 1.50-4.89) show that attendance at conversion practices is related to individuals being at least one-and-a-half times as likely to have a mental health diagnosis (including almost three-and-a-half times as likely to have been diagnosed with post-traumatic stress disorder/PTSD, and almost five times as likely to have been diagnosed with schizophrenia).

Most LGBTQA + youth conversion attendees and nonattendees now preferred only $L G B T Q A+$ inclusive/only counselling services (58.4\% vs. $57.6 \%$ ) above non-inclusive services, and in-person general counselling ( $71.5 \%$ vs. $68 \%)$ above text/web chat or telephone general counselling. However, telephone counselling preference increased (to $8.4 \%$ from $4.9 \%$ for conversion attendees, vs. to $4.9 \%$ from $2.1 \%$ for non-attendees) for sessions regarding self-harm and/or suicide.

\section{Discussion}

\section{Emphasising Specific Demographic Factors}

The portion of Australian LGBTQA + youth who attended 'conversion counselling, group work, programs and interventions' was smaller than the 4.9-7\% of Australian students reporting school-based exposure to the 'gay people should become straight' messaging in recent studies (Jones, 2015; 2020). Thus, conversion ideology — even narrowly defined around gay identity - may be more widespread than conversion practices, or easier to capture via surveys. Combining the groups who answered 'Yes', 'Don't know' and 'Prefer not to say' showed a total of $7.3 \%$ attended or potentially attended conversion practices, matching Australian and UK conversion ideology figures (Jones, 2015; UK Government Equalities Office, 2018), though falling below Iran and South Korea's 16\% + figures (Bishop, 2019). Given over half of LGBTQA + youth attended conversion practices in the
Table 6 Mean (SD) of LGBTIQA + youths' selfreported psychological health and well-being as a function of attending or not attending conversion practices

\begin{tabular}{|c|c|c|c|c|c|}
\hline & \multicolumn{2}{|c|}{$\begin{array}{l}\text { Conversion practice attendance, } \\
M(S D)\end{array}$} & \multicolumn{3}{|c|}{ Statistics } \\
\hline & Reported & Not reported & $t$ & $p$ & Cohen's $d$ \\
\hline \multicolumn{6}{|l|}{ Psychological health } \\
\hline Anxiety & $12.77(6.23)$ & $10.36(5.84)$ & -6.03 & $<.001$ & 0.40 \\
\hline Psychological distress & $33.43(9.64)$ & $27.72(8.83)$ & -6.01 & $<.001$ & 0.40 \\
\hline Self-reported health & $2.70(1.09)$ & $2.91(0.98)$ & 3.12 & $<.001$ & 0.20 \\
\hline Self-reported well-being & $2.11(0.98)$ & $2.36(1.01)$ & 3.95 & $<.001$ & 0.25 \\
\hline
\end{tabular}

Variables that are associated with attendance at conversion practices at a statistically significant level $(p<.05)$ are presented in boldface 
Table 7 Frequency (\%) of LGBTIQA + youths' suicidality and self-harming as a function of attending or not attending conversion practices

\begin{tabular}{|c|c|c|c|c|c|c|c|}
\hline & \multicolumn{2}{|c|}{$\begin{array}{l}\text { Conversion practice attend- } \\
\text { ance, } N(\%)\end{array}$} & \multicolumn{2}{|c|}{$\begin{array}{l}\text { No conversion practice } \\
\text { attendance, } N(\%)\end{array}$} & \multirow[b]{2}{*}{$\chi^{2}$} & \multirow[b]{2}{*}{$p$} & \multirow[b]{2}{*}{ Odds ratio } \\
\hline & Reported & Not reported & Reported & Not reported & & & \\
\hline \multicolumn{8}{|l|}{ Suicidality } \\
\hline Thoughts & $216(92.3 \%)$ & $18(7.7 \%)$ & $4614(82.1 \%)$ & $1008(16.9 \%)$ & 16.29 & $<.001$ & 2.62 \\
\hline Plans & $168(73.4 \%)$ & $61(26.6 \%)$ & $2687(49.3 \%)$ & $2759(50.7 \%)$ & 50.73 & $<.001$ & 2.83 \\
\hline Attempts & $127(57.2 \%)$ & $95(42.8 \%)$ & $1401(25.8 \%)$ & $4029(74.2 \%)$ & 106.45 & $<.001$ & 3.85 \\
\hline \multicolumn{8}{|l|}{ Self-harm } \\
\hline Thoughts & $214(92.2 \%)$ & $18(7.8 \%)$ & $4577(81.6 \%)$ & $1032(17.3 \%)$ & 17.11 & $<.001$ & 2.68 \\
\hline Behaviours & $137(79.2 \%)$ & $36(20.8 \%)$ & $2404(54.8 \%)$ & $1985(45.2 \%)$ & 40.22 & $<.001$ & 3.14 \\
\hline
\end{tabular}

Variables that are associated with attendance at conversion practices at a statistically significant level $(p<.05)$ are presented in boldface past year, Australian conversion practices were 'current'. It is possible that there is a greater number of LGBTQA + youth attending conversion practices than evident in these data, as younger participants perhaps required more nuanced definitions or safer/private spaces for responding, and limitations of the study included its lack of such definitions and spaces. These are recommended for future studies.

The findings show a strong comparative representation of cisgender males in those who experienced conversion practices, consistent with the emphasis on white gay males in US adult research and gay males in African and Asian adult research (Bennett, 2003; Bishop, 2019; Erzen, 2006; Gerber, 2012; Waidzunas, 2015; Wolkomir, 2006), and contrasted against UK and Australian adult research-though this may change as new conversion practice movements targeting gender diversity spread (UK Government Equalities Office, 2018). Whilst research has found that trans and gender diverse Australians often became atheist adults, viewing religion as incommensurate with their identity (Jones,
2015), this is not the case for many LGBTQA + youth. Postconversion supports that are broadly religion-friendly are important given participants attending conversion practices often retained religious affiliations.

\section{Negative Social, Socio-Behavioural, Health and Well-being Outcomes}

Attending conversion practices was linked to higher identity disclosure to social networks. This may be because conversion practices can result from disclosures to family and community (APA Task Force, 2009). LGBTQA + youth who had attended conversion practices reported significantly less social support and more negative remarks on LGBTQA + topics (likely due to the increased attention on such topics in conversion efforts). In addition, they experienced considerably more verbal and physical harassment both generally and recently-perhaps within conversion practices or the contexts impelling their participation (perhaps both), although our data do not allow us to

Table 8 Frequency (\%) of LGBTIQA + youths' history of illness as a function of attending or not attending conversion practices

\begin{tabular}{|c|c|c|c|c|c|c|c|}
\hline & \multicolumn{2}{|c|}{ Conversion practice attendance, $N(\%)$} & \multicolumn{2}{|c|}{ No conversion practice attendance, $N(\%)$} & \multicolumn{2}{|c|}{ Statistics } & \multirow[b]{2}{*}{ Odds ratio } \\
\hline & History of illness & No history of illness & History of illness & No history of illness & $\overline{\chi^{2}}$ & $p$ & \\
\hline Depression & $166(64.8 \%)$ & $90(35.2 \%)$ & $2651(44.6 \%)$ & $3298(55.4 \%)$ & 40.73 & $<.001$ & 2.30 \\
\hline GAD & $150(58.6 \%)$ & $106(41.4 \%)$ & $2738(46.0 \%)$ & $3211(54.0 \%)$ & 15.58 & $<.001$ & 1.66 \\
\hline PTSD & $62(24.2 \%)$ & $194(75.8 \%)$ & $545(9.2 \%)$ & $5404(90.8 \%)$ & 63.05 & $<.001$ & 3.27 \\
\hline Bipolar disorder & $19(7.4 \%)$ & $237(92.6 \%)$ & $165(2.8 \%)$ & $5784(97.2 \%)$ & 18.43 & $<.001$ & 2.97 \\
\hline Panic disorder & $33(12.9 \%)$ & $223(87.1 \%)$ & $420(7.1 \%)$ & $5529(92.9 \%)$ & 12.33 & $<.001$ & 1.94 \\
\hline Social phobia & $31(12.1 \%)$ & $225(87.9 \%)$ & $502(8.4 \%)$ & $5447(91.6 \%)$ & 4.21 & .040 & 1.50 \\
\hline Agoraphobia & $8(3.1 \%)$ & $248(96.9 \%)$ & $71(1.2 \%)$ & $5878(98.8 \%)$ & 7.29 & .007 & 2.67 \\
\hline OCD & $35(13.7 \%)$ & $221(86.3 \%)$ & $392(6.6 \%)$ & $5557(93.4 \%)$ & 19.21 & $<.001$ & 2.25 \\
\hline Schizophrenia & $9(3.5 \%)$ & $247(96.5 \%)$ & $44(0.7 \%)$ & $5905(99.3 \%)$ & 22.33 & $<.001$ & 4.89 \\
\hline Eating disorder & $50(19.5 \%)$ & $206(80.5 \%)$ & $660(11.1 \%)$ & $5289(88.9 \%)$ & 17.24 & $<.001$ & 1.94 \\
\hline
\end{tabular}

Variables that are associated with attendance at conversion practices at a statistically significant level $(p<.05)$ are presented in boldface $G A D$ generalised anxiety disorder, $P T S D$ post-traumatic stress disorder, $O C D$ obsessive compulsive disorder 
determine with certainty. Such rejection and harassment may partially explain the increased rates of feeling unsafe, truancy and disengagement in educational institutions and decreased employment and sports participation among young people who had attended conversion practices - however, this requires further research. Given Australian governments legally require school attendance, they hold responsibility to redress schoolbased harassment through exemption-free policy protections for LGBTQA + youth and inclusive curricula.

LGBTQA + youth who attended conversion practices also experienced elevated levels of homelessness compared to those who had not attended. This experience was often directly linked to their LGBTQA + identities including related mental health issues and family rejection. Such impacts were, for many, current and ongoing and potentially cyclical. Engaging in education, sport or employment is difficult without a home address; as is gaining a residence without qualifications, social contacts and/or income.

Research shows that LGBTQA + youth experience greater vulnerability to poor health and well-being (Australian Bureau of Statistics, 2012, 2018; Jones, et al., 2016; Lawrence, et al., 2015); however, LGBTQA + youth who attended conversion practices reported poorer health, and higher rates of smoking and drug use than those who did not. They were also at considerably higher risk of psychological distress and mental health conditions, self-harm and suicide than other LGBTQA + youth-echoing the higher risks seen in previous studies for Australian students exposed to conversion ideology. These risks may be under-stated, as many participants who attended conversion left well-being survey questions unanswered.

The significant social, cultural, physical and mental harms associated with conversion practices found in this study support the need for legislation banning these practices whilst being mindful of the impacts to young conversion practice attendees who may engage in promoting conversion to peers. However, banning conversion practices is not enough. These data suggest a need for more inclusive LGBTQA + youth services across Australian healthcare, education, housing and employment generally - which can contain hostile environments. For those who attended conversion practices, there is a greater need for in-person (as well as text/web chat and phone-based) crisis care and general counselling services that is both LGBTQA + inclusive and religion-friendly. It is imperative to support LGBTQA + and religious identities coexisting in more affirming frameworks (Jones et al., 2021), and socio-behavioural/institutional re-engagements in efforts to break potential cycles of exclusion.

\section{Strengths and Limitations}

Two key strengths of this study are that it provided a large sample, and the first Australian LGBTQA + youth sample, for a study actively exploring conversion practices (not just conversion ideologies). Over a quarter of the cohort were gender diverse-substantially more than the $3.1 \%$ of Australian LGBTQA + samples previously (Hillier et al., 2010), reflecting increased structural supports available to Australian gender diverse youth (Smith et al., 2014). Moreover, sexualities in the new cohort show increased trends of more frequent use of bisexual and non-binary sexual identities by same-gender-attracted females and gender minorities (Hillier et al., 2010). Contrastingly, there was greater sexual variability among Australian cisgender male youth, who previously mostly (82\%) identified as gay. These diverse participants enabled the study to show the conversion push impacts a greater variety of individuals than shown in previous Australian data.

Limitations included that the survey was a cross-sectional LGBTQA + study, privileging breadth of coverage over detail for any one sub-group, and potentially excluding those claiming conversion practices 'worked' (identifying as cisgender and straight). Further, the study only reported on formal conversion practices; informal conversion practices (potentially delivered via activities such as everyday pastoral care or youth-led prayer groups and including for example casual compliments on gender-conforming outfits) can operate in subtle ways unobvious to participants and (therefore) not picked up in surveys. Thus, the conversion practice attendance figure should be considered a conservative minimum. Future research should define both conversion ideology and conversion practices in expanded questions supporting participants' understanding, provide 'safe spaces' supporting younger participants' ability to safely complete the survey without adult reprisal and explore emerging legislative impacts to understand conversion bans' effectiveness.

\section{Conclusions}

This study reflected Mallory et al. (2019) estimates that youth are exposed to conversion practices at around half the rate of their (and international LGBTQ + adults') exposure to conversion ideology messaging in Western contexts. It also supported LGBTQA + adult UK findings showing that conversion practices were experienced by people of diverse gender identities, cultural and religious backgrounds, and US findings emphasising targeting of religious cisgender males. It expands Canadian findings linking conversion practices to significant socio-behavioural and health/well-being harms and to mental health diagnoses. Given the prevalence, severity and range of impacts of conversion practices reported by participants in this study, the findings support calls for conversion practice bans and for inclusive educational, employment, healthcare and mental health services mediating negative impacts for affected youth. 
Acknowledgements Insights were contributed by community advisory boards, Lynne Hillier and Anne Mitchell.

Funding Victorian Government Department of Premier and Cabinet, ACT Government Office for LGBTIQA + Affairs, NSW Department of Health, SHINE SA and SA Chief Psychiatrist Office.

Availability of Data and Materials Upon application to authors at their discretion.

Open Access This article is licensed under a Creative Commons Attribution 4.0 International License, which permits use, sharing, adaptation, distribution and reproduction in any medium or format, as long as you give appropriate credit to the original author(s) and the source, provide a link to the Creative Commons licence, and indicate if changes were made. The images or other third party material in this article are included in the article's Creative Commons licence, unless indicated otherwise in a credit line to the material. If material is not included in the article's Creative Commons licence and your intended use is not permitted by statutory regulation or exceeds the permitted use, you will need to obtain permission directly from the copyright holder. To view a copy of this licence, visit http://creativecommons.org/licenses/by/4.0/.

\section{References}

ACT Government. (2020). Sexuality and Gender Identity Conversion Practices Bill 2020. Canberra: ACT Government.

APA Task Force. (2009). Appropriate therapeutic responses to sexual orientation. American Psychological Association.

Australian Bureau of Statistics. (2012). Use of the Kessler Psychological Distress Scale in ABS Health Surveys, Australia [Internet]. 6. 1.18. Available from: https://www.abs.gov.au/ausstats/abs@.nsf/ Lookup/4817.0.55.001Chapter92007-08

Australian Bureau of Statistics. (2018). 4221.0 - Schools, Australia, 3.10.18. Available from: http://www.abs.gov.au/ausstats/abs@. $\mathrm{nsf} / \mathrm{mf} / 4221.0$

Australian Institute of Family Counselling. (2017). Get equipped. Mitchell: AIFC.

Australian Psychological Society. (2007). Code of ethics. Melbourne: APS.

Beckstead, A. (2020). Can we change sexual orientation? Archives of Sexual Behaviour., 41(1), 121-134.

Bennett, J. (2003). Love me gender. Texts and Performance Quarterly., 23(4), 331-352.

Bishop, A. (2019). Harmful treatment. Outright Action International.

Bombak, A. (2013). Self-rated health and public health. Front Public Health, [Internet]. 20.5.13. Available from: https://www.ncbi.nlm. nih.gov/pmc/articles/PMC3855002/

Csabs, C., Despott, N., Morel, B., Brodel, A., \& Johnson, R. (2020). SOGIEC survivor statement. Brave.

Erzen, T. (2006). Straight to Jesus. UCP.

Gerber, L. (2012). Seeking the straight and narrow. University of Chicago.

Health Complaints Commissioner. (2019). Inquiry into conversion therapy. Melbourne: Victorian Government.

Hillier, L., Jones, T., Monagle, M., Overton, N., Gahan, L., Blackman, J., et al. (2010). Writing themselves in 3. Melbourne: ARCSHS.

Hill, L. A. (2019). Tasmanian Law Reform Institute to conduct inquiry into conversion practice. OUTinPerth. Accessed 12.12.19. Retrieved from. https://www.outinperth.com/tasmanian-lawreform-institute-to-conduct-inquiry-into-conversion-practice/? link_id=6\&can_id=ac2b07a77286b0fcaba82d673345c2e2\& source $=$ email-its-time-to-end-lgbtq-conversion-practices- $2 \&$ email_referrer=email_891137___subject_1218954\&email_ subject=update-on-ending-conversion-practices

Jones, T. (2015). Policy and gay, lesbian, bisexual, transgender and intersex students. Cham, Heidelberg, New York, Dordrecht and London: Springer.Jones, T. (2020). A student-centred sociology of Australian education: Voices of experience, Cham: Springer.

Jones, T. (2020). A Student-Centred Sociology of Australian Education: Voices of Experience. Springer: Cham.

Jones, T., del Pozo de Bolger, A., Dunne, T., Lykins, A., \& Hawkes, G. (2015). Female-to-male (FtM) transgender people's experiences in Australia. Springer.

Jones, T., \& Hillier, L. (2012). Sexuality education school policy for GLBTIQ students. Sex Education., 12(4), 437-454.

Jones, T., Smith, E., Ward, R., Dixon, J., Hillier, L., \& Mitchell, A. (2016). School experiences of transgender and gender diverse students in Australia. Sex Education., 16(2), 156-171.

Jones, T. W., Jones, T., Power, J., Despott, N., \& Pallotta-Chiarolli, M. (2021). Healing spiritual harms. Australian Research Centre in Sex Health and Society, Melbourne.

Keane, C. (2009). Choices. Melbourne: Acorn.

Lawrence, D., Johnson, S., Hafekost, J., Boterhoven de Haan, K., Sawyer, M., Ainley, J., et al. (2015). The mental health of children and adolescents. Canberra: Department of Health.

Mac-Iyalla, D. (2014). Changing attitudes through the example of Jesus. Transition., 114(1), 70-83.

Mallory, C., Brown, T., \& Conron, K. (2019). Conversion therapy and $L G B T$ youth. Los Angeles: Williams Institute.

QLD Government. (2020). Health Legislation Amendment Bill 2019. Brisbane: Queensland Government.

Richards, S., \& Skujins, A. (2020). SA move to outlaw conversion therapy. InDaily. Accessed 16.7.20. Retrieved from https://indaily.com. au/news/2020/07/16/sa-move-to-outlaw-conversion-therapy/?link $\mathrm{id}=5 \&$ can_id $=$ ac2b07a77286b0fcaba82d673345c2e $2 \&$ source $=$ email-its-time-to-end-lgbtq-conversion-practices-2\&email_refer rer=email_891137__subject_1218954\&email_subject=updateon-ending-conversion-practices

Serovich, J., Craft, S., Toviessi, P., Gangamma, R., McDowell, T., \& Grafsky, E. A. (2008). Systematic review of the research base on sexual reorientation therapies. Journal of Marital and Family Therapy., 34(2), 227-238.

Smith, E., Jones, T., Ward, R., Dixon, J., Mitchell, A., \& Hillier, L. (2014). From blues to rainbows. Melbourne: ARCSHS.

UK Government Equalities Office. (2018). National LGBTIQ+ Survey. Manchester: United Kingdom Government Equalities Office.

United Nations. (2020). Report on conversion therapy. UN.

Venn-Brown, A. (2015). Sexual orientation change efforts within religious contexts. Sensoria., 11(1), 81-91.

Victorian Government. (2021). Change or Suppression (Conversion) Practices Prohibition Bill 2020. Melbourne: Victorian Parliament.

Waidzunas, T. (2015). The straight line. University of Minnesota.

WA Parliamentary Council. (2020). McGowan Government Election Commitments. Hansard [Internet]. 18.3.20:[p1497c-516a]. Available from: https://www.parliament.wa.gov.au/Hansard/Hansard. nsf/0/0c7df2e4032e8f2548258531002809a2/\$FILE/C40\%20S1\% 2020200318\%20p1497c-1516a.pdf.

Wolkomir, M. (2006). Be not deceived. Rutgers University.

Yarhouse, M. (2015). Understanding gender dysphoria. Downers Grove: InterVarsity.

Publisher's Note Springer Nature remains neutral with regard to jurisdictional claims in published maps and institutional affiliations. 